\title{
Analisa Pengaruh Kecepatan Putaranterhadap Kualitas Produk Pada Mesin Three In One
}

\author{
K. A. Widi, N. Sudiasa, W. Sujana, F. Qadhafi ${ }^{1}$ \\ ${ }^{1}$ Teknik Mesin Institut Teknologi Nasional Malang \\ Email: aswidi@yahoo.com
}

\begin{abstract}
Mesin Pembuat Lidi Bambu Three in One Adalah sebuah alat mesin yang berfungsi untuk membuat lidi bambu yang produknya sebagai tusuk sate, tusuk gigi, tusuk bakso, lidi sangkar burung. Mesin pembuat lidi atau tusuk sate yang kami buat mempunyai kenggulan 3 proses sekaligus dalam pengerjaanya. Pertama yaitu proses penipisan, proses ini menipiskan bambu yang masih mempunyai ketebalan dan berbentuk balok. Kedua adalah proses perajang, prosesnya merajang menjadi belahan bambu kotak kecil-kecil. Ketiga adalah penyerutan yaitu proses dari perajangan bambu lidi yang masih berprofil kotak akan di serut menjadi profil bulat. Dalam pembuatan mesin tusuk sate memerlukam komponen besar yaitu motor sebagai penggerak, dan komponen pendukung lainya seperti besi siku sebagai kerangka, pully, rantai gir motor, roll karet, bering besi as. Bahan yang digunakan untuk membuat benda uji adalah sebuah bambu yang tua kisaran umur 2 tahun, kemudian di potong dan di belah kemudian akan dimasukkan ke mesin untuk melalui pisau penipis dilanjutkan kepisau perajang (dibelah kecil-kecil berbentuk profil kotak). Selanjutnya akan di masukkan kembali melalui pisau serut, pisau yang berbentuk kerucut sehingga akan membentuk lidi berbentuk profil bulat. Analisis data menggunakan dengan meninjau grafik yang terbentuk, data yang diperlukan berupa data kecepatan putaran (rpm) dan produk lidi, kemudian dibandingkan hasil data pengujian memakai kecepatan putaran (rpm) rendah 2000, sedang 2500, dan tinggi 3000. Pengujian menggunakan panjang produk $25 \mathrm{~cm}$ dengan rata-rata jumlah sampel 60 . Percobaan kecepatan 2000 didapatkan dari semua percobaan didapat rataan gagal produk sebanyak 3\%. Percobaan kecepatan 2500 didapatkan dari semua percobaan didapat rataan gagal produk sebanyak 1,6\%. Percobaan kecepatan 3000 didapatkan dari semua percobaan didapat rataan gagal produk sebanyak $9,6 \%$.
\end{abstract}

Keywords Mesin three in one, kecepatan putaran, lidi, bamboo, rpm.

Paper type Research paper

\section{PENDAHULUAN}

Bambu memegang peranan penting dalam kehidupan masyarakat, bamboo dikenal oleh masyarakat memiliki beberapa sifat yang baik untuk dimanfaatkan sifat-sifatbambu antara lain yaitu: batangnya kuat, ulet, lurus, rata, keras, mudah diolah, dan mudah dibentuk. Bambo juga relatif murah harga jualnya di bandingkan dengan bahan material pada umumnya, dikarenakan bambu banyak ditemukan disetiap kota di Jawa Timur yaitu adalah Kota Malang.

Munculnya industri-industri kerajinan bambu membuat para pengusaha kerajinan berlomba dan meningkatkan kualitas dan kuantitas dari produk yang mereka hasilkan.Para industri kecil selalu dituntut untuk menghasilkan produknya dalam jumlah yang besar. Mengingat kebutuhan yang cukup besar, maka banyak bermunculan gagasan untuk menciptakan alat yang dapat membantu para industry kecil kerajinan bambu untuk meningkatkan kualitas dan kuantitas produknya

Harapan dari alat ini adalah agar dapat menghasilkan produk dalam jumlah besar dalam waktu yang singkat.

Pembuatan alat bantu atau mesin untuk mempercepat proses pengerjaan produk kerajinan bambu sangat diperlukan oleh para pengrajin di industri kecil dan menengah di Malang. Dengan adanya fenomena dan maraknya pembuatan mesin pembuat bitting dupa penulis mendapatkan gagasan untuk melakukan pengujian yang bertujuan untuk mengetahui kecepatan (rpm) mesin diesel berapa yang bagus untuk hasil yang maksimal produk bitting dupa.

\section{TINJAUAN PUSTAKA}

Kebanyakan para penjual tusuk sate masilah tradisional atau menggunakan cara manual dalam membuat tusuk sate. Sehingga akan sangat lama dalam pemroduksian lidi tusuk sate dan sangat lelah pengerjaanya, banyak tenaga kerjanya, waktu yang diperlukan lama serta juga sedikit hasilnya alias tidak efektif dan efisien, oleh karena itu kami mencoba membuat alat mesin pembuat lidi bambu atau tusuk sate.

Mesin pembuat lidi atau tusuk sate yang kami buat mempunyai kenggulan yaitu langsung mempunyai 3 proses sekaligus dalam pengerjaanya. Yang pertama yaitu proses penipisan, proses ini menipiskan bambu yang masih mempunyai ketebalan dan berbentuk balok. Yang kedua adalah proses perajang, prosesnya merajang menjadi belahan bambu kotak kecil-kecil. Yang ketiga adalah penyerutan yaitu proses dari perajangan bambu lidi yang masih berprofil kotak akan di serut menjadi profil bulat. 


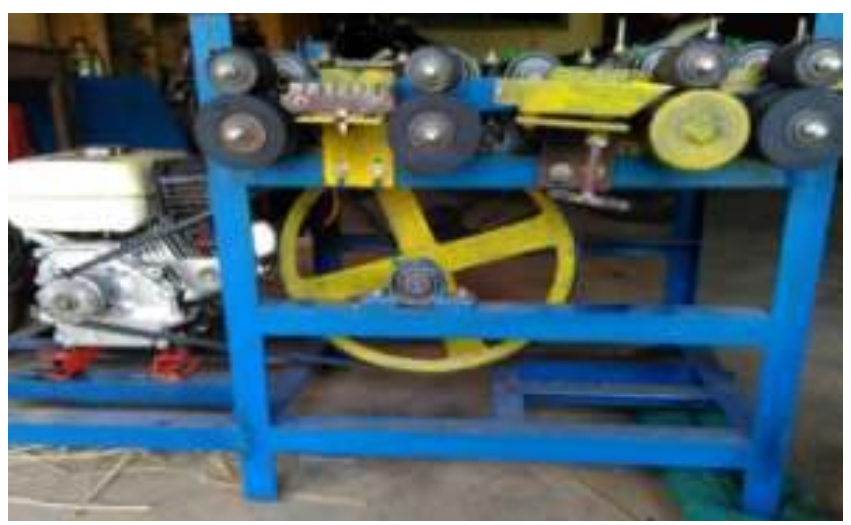

Fig. 1. Mesin tusuk sate three in one

Prinsip Kerja Mesin Pembuat Lidi Bambu adalah mesin penyerut bambu dibuat dan dijual untuk mengatasi kebutuhan seperti tusuk sate, lidi dupa, tusuk gigi, dll di Indonesia. Adanya mesin penyerut bambu membantu kebutuhan pengusaha sate, bakso, sosis dan lain-lain yang tak lain menggantungkan pada tangan manusia dalam membuatnya. Mesin penyerut bambu dimiliki atau di butuhkan para pengusaha lidi bambu untuk memproduksi tusuk lidi dalam jumlah yang besar. Mesin pembuat lidi bambu ini adalah mesin serut bambu. Berikut ini cara kerja mesin serut bambu mulai dari bahan berupa bambu hingga menjadi tusuk sate, lidi dupa, tusuk gigi dan lain-lain.

\section{METODOLGI PENELITIAN}

Alat dan Bahan yang digunakan dan fungsi komponen-komponen mesin 3 in 1 pembuat lidi adalah :

- Motor bensin, Sebagai penggerak utama untuk menggerakkan mesin pembuat tusuk sate.

- Puli, Sebagai penerus putaran dari puli motor bensin yang putaranya akan di teruskan menuju putaran as dan rol.

- Rantai, Penerus putaran dari as satu menuju ke as yang lainya.

- As, Sebagai dudukan penompang penggerak rol.

- Roll karet dan besi, Sebagai penjepit berjalanya bambu biting yang akan di tipiskan, diserut (profil bulat), dan di rajang (belah kecil-kecil profil kotak).

- Bearing, Untuk mengurangi gesekan dari suatu putaran

- Pisau penipis, perajang, serutan

\section{ANALISIS DAN PEMBAHASAN}

\begin{tabular}{cc} 
TABLE I. & Data Hasil Pengujian Kecepatan Pada Proses P \\
\cline { 2 - 3 }$\left(\begin{array}{c}\text { Putaran Mesin } \\
(\mathrm{rpm})\end{array}\right.$ & $\begin{array}{c}\text { Jumlah Kegagalan } \\
\text { Produk Lidi (\%) }\end{array}$ \\
\hline & 5 \\
& 3 \\
Rata-rata & 1 \\
& 3 \\
\hline & 3 \\
& 2 \\
Rata-rata & 0 \\
& 1,6 \\
\hline & 10 \\
Rata-rata & 10 \\
\end{tabular}

Hasil diatas penguji menggunakan panjang produk $25 \mathrm{~cm}$ dengan rata-rata jumlah sampel 60 , pendataan dari proses penyerutan didapatkan kecepatan rendah 2000, kecepatan sedang 2500, dan kecepatan tinggi 3000 rpm. Data dibentuk dalam grafik untuk dibandingkan antara kecepatan rendah, sedang dan tinggi. 


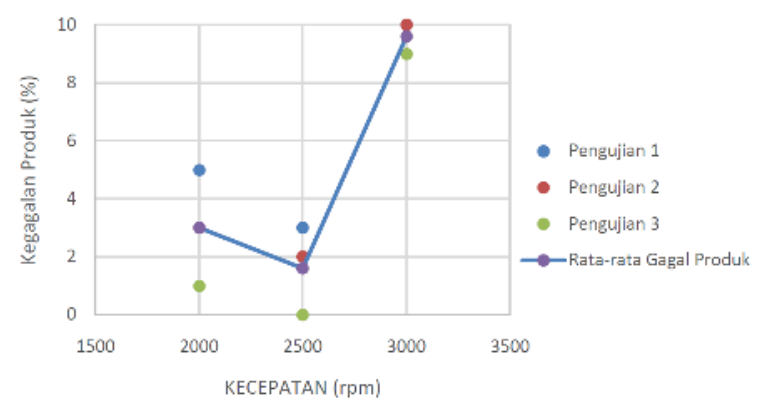

Fig. 2. Grafik Hasil Percobaan Semua Kecepatan

Pada percobaan pertama peneliti menggunakan kecepatan rendah yaitu $2000 \mathrm{rpm}$. Pada kecepatan 2000 peneliti menggunakan specimen bambu yang masih produk setengah jadi yang didapat dari proses perajang. Pada pengujian pertama peneliti mengambil jumlah sampel sebanyak 60 buah dan ditemukan cacat sebanyak 5\%. Pengujian saya lakukan sebanyak tiga kali dengan tujuan agar semakin terlihat data yang dihasilkan. Pengujian kedua menggunakan jumlah sampel yang sama dan didapatkan gagal produk sebanyak 3\%. Dan pengujian ketiga didapatkan gagal produk sebanyak $1 \%$.

Pada percobaan kecepatan 2000 didapatkan dari semua percobaan didapat rataan gagal produk sebanyak $3 \%$. Meskipun menurun pada persentase kegagalan produk akan tetapi masih ditemukan banyak produk yang gagal ditemukan. Ini dapat disebabkan oleh tidak stabilnya kecepatan pada diesel. Dan banyak ditemukan rataan cacat tidak bulat sempurna pada hasil penyerutan. Dapat dilihat pada Fig 3.

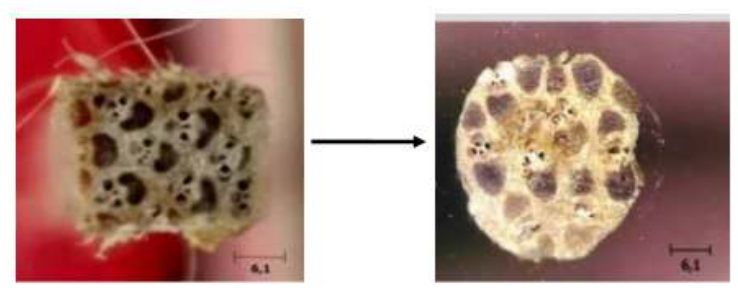

Fig. 3. Lidi Kotak dan Bulat

Pada percobaan kedua peneliti menggunakan kecepatan sedang yaitu $2500 \mathrm{rpm}$. Pada kecepatan 2500 peneliti menggunakan specimen bambu yang masih produk setengah jadi yang didapat dari proses perajang. Pada pengujian pertama peneliti mengambil jumlah sampel sebanyak 60 buah dan ditemukan cacat sebanyak 3\%. Pengujian saya lakukan sebanyak tiga kali dengan tujuan agar semakin terlihat data yang dihasilkan. Pengujian kedua menggunakan jumlah sampel yang sama dan didapatkan gagal produk

sebanyak $2 \%$. Dan pengujian ketiga didapatkan gagal produk sebanyak $0 \%$.

Pada percobaan kecepatan 2500 didapatkan dari semua percobaan didapat rataan gagal produk sebanyak 1,6\%. Dari percobaan kedua dapat dilihat dari tiga kali pengujian persentase jumlah cacat menurun sampai tidak didapatkan cacat sama sekali pada pengujian ketiga. Ini dikarenakan kecepatan putaran mesin stabil sehingga produk proses penyerutan sedikit yang mengalami gagal produk dibandingkan dengan percobaan pertama. Pada percobaan ketiga banyak ditemukan gagal produk yang banyak ini dikarenakan kecepatan putaran yang tinggi menyebabkan alat bergetar dan bergerak jadi proses penyerutan tidak berjalan dengan maksimal sehingga banyak cacat berupa patah, banyak limbah yang terbuang dan mengganjal pada pisau penyerut.

\begin{tabular}{ccc} 
TABLE II. & DATA Hasil KuAt LeNTUR Lidi \\
\hline $\begin{array}{c}\text { Putaran Mesin } \\
(\mathrm{rpm})\end{array}$ & $\begin{array}{c}\text { Sudut } \\
\left({ }^{\circ}\right)\end{array}$ & $\begin{array}{c}\text { Beban } \\
(\text { gram })\end{array}$ \\
\hline & 10 & 320 \\
& 20 & 623 \\
30 & 850 \\
& 10 & 400 \\
& 20 & 750 \\
& 30 & 1080 \\
10 & 300 \\
& 20 & 550 \\
& 30 & 725 \\
\hline
\end{tabular}




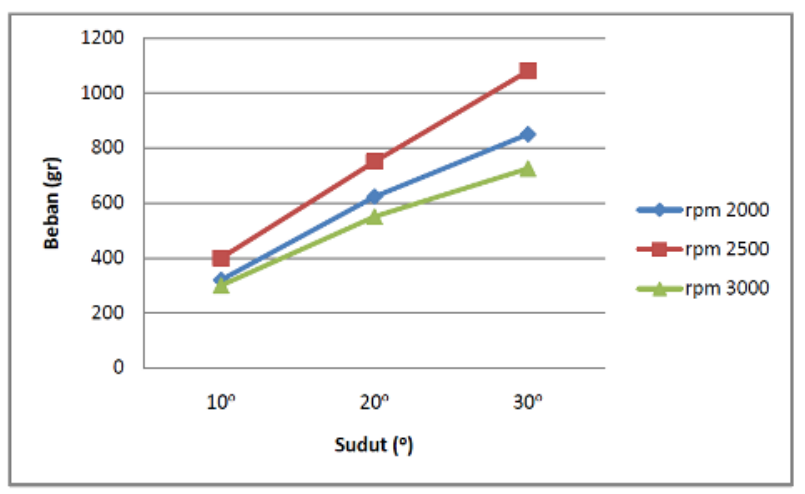

Fig. 4. Grafik Kuat Lentur Lidi

Pengujian kuat lentur lidi bambu adalah pengujian yang bertujuan untuk mengetahui kekuatan lidi. Untuk pengujian kuat lentur saya menggunakan 1 sampel dari masing-masing lidi adalah $25 \mathrm{~cm}$. Pengujian dilakukan dengan mengambil data besarnya beban dan sudut, untuk sudut yang saya gunakan adalah sudut $10^{\circ}, 20^{\circ}$,dan $30^{\circ}$. Pada Fig 4 memperoleh data lidi untuk kecepatan 2000 besar sudut $10^{\circ}$ pembebananya 320 gram, sudut $20^{\circ}$ pembebananya 623 gram, dan $30^{\circ}$ pembebananya 850 gram. Dari grafik tersebut mengalami kenaikan dikarenakan beban sudut yang dinaikkan sehingga beban juga ikut naik.

Pada keceptan 2500 besar sudut $10^{\circ}$ pembebananya 400 gram, sudut $20^{\circ}$ pembebananya 750 gram, dan $30^{\circ}$ pembebananya 1080 gram. Dari grafik tersebut mengalami kenaikan dikarenakan beban sudut yang dinaikkan sehingga beban juga ikut naik. Selanjutnya pada keceptan 3000 besar sudut $10^{\circ}$ pembebananya 300 gram, sudut $20^{\circ}$ pembebananya 550 gram, dan $30^{\circ}$ pembebananya 725 gram. Dari grafik tersebut mengalami kenaikan dikarenakan beban sudut yang dinaikkan sehingga beban naik. Jadi untuk lidi diatas kita dapat mengambil perbandingan dan mengambil kesimpulan, hasil lidi kecepatan sedang 2500 lebih kuat dibandingkan dengan kecepatan lainnya.Dikarenakan pada kecepatan tersebut mesin berjalan dengan stabil dan tidak ada kendala apapun. Sedangkan dikecepatan tinggi 3000 didapatkan data tidak kuat dikarenakan pada proses penyerutan mesin bergetar dan tidak stabil sehingga pada prosesnya banyak kendala.

\section{KESIMPULAN}

- Peneliti dapat menyimpulkan pada alat pembuat tusuk sate menggunakan mesin diesel pada proses penyerutan yang cocok pada kecepatan 2500 rpm karena kecepatannya stabil sehingga proses berjalan dengan lancar tanpa hambatan.

- Penguji dapat mengambil perbandingan dan mengambil kesimpulan, hasil lidi kecepatan sedang 2500 lebih kuat dibandingkan dengan kecepatan lainnya. Dikarenakan pada kecepatan tersebut mesin berjalan dengan stabil dan tidak ada kendala apapun. Sedangkan dikecepatan tinggi 3000 didapatkan data tidak kuat

\section{SARAN}

Untuk penelitian selanjutnya bisa dengan memvariasikan antara mesin diesel dan dinamo listrik. Untuk penelitian selanjutnya dapat merubah desain agar lebih ringan

\section{DAFTAR PUSTAKA}

[1] Eduengineering.wordpress.(2015). Prinsip Kerja Motor Bakar dan Komponenya, https://eduengineering.wordpress.com/2015/01/10/prinsip-kerjamotorbakar-dan-komponennya.

[2] Gunawan.(2009). Kajian Sifat-sifat Finishing Anyaman Bambu Tali (Gigantochloa apus (J. A \& J. H. Schultes) Kurz). Skripsi IPB : Bogor ISO 22156 (2004) Bamboo - Structure Design and ISO 22157-1: 2004 (E) Bamboo - Determination of physical and mechanical properties - Part 1: Requirements and Part 2: Laboratory manual. INBAR - 2004.

[3] Marzuamin, A.(2009). Analisa Sifat-sifat Fisik dan Mekanik Material Bambu yang Paling Banyak Dipakai dan Mayoritas Terdapat di Jawa Timur Sebagai Elemen Bangunan.Tesis ITS : Surabaya

[4] Morisco, 1996 ; Bambu sebagai Bahan Rekayasa, Pidato Pengukuhan Jabatan Lektor Kepala Madya dalam Bidang Ilmu Teknik Sipil, Fakultas Teknik UGM.

[5] Prihtiyani, E.(2010). Kerajinan Bambu Tembus Supermarket, Laporan wartawan KOMPAS, Jumat, 23 April 2010.

[6] Sulthoni A., (1983). Petunjuk Ilmiah Pengawetan Bambu Tradisional dengan perendaman Dalam Air, International Development Research Center Ottawa, Canada. 